\title{
Metal-Organic Framework Encapsulated Whole-Cell Vaccines Enhance Humoral Immunity against Bacterial Infection
}

Michael A. Luzuriaga, ${ }^{1,6}$ Fabian C. Herbert, ${ }^{1,6}$ Olivia R. Brohlin, ${ }^{1}$ Jashkaran Gadhvi, ${ }^{2}$ Thomas Howlett, ${ }^{1}$ Arezoo Shahrivarkevishahi, ${ }^{1}$ Yalini H. Wijesundara, ${ }^{1}$ Sundharamani Venkitapathi, ${ }^{2}$ Kavya Veera, ${ }^{2}$ Ryanne Ehrman, ${ }^{1}$ Candace E. Benjamin, ${ }^{1}$ Sarah Popal, ${ }^{1}$ Michael D. Burton, ${ }^{3}$ Molly A. Ingersoll, ${ }^{5}$ Nicole J. De Nisco, ${ }^{*}, 2$ and Jeremiah J. Gassensmith*,1,4

1 Department of Chemistry and Biochemistry, ${ }^{2}$ Department of Biological Sciences, ${ }^{3}$ School of Brain and Behavioral Science, 4 Department of Biomedical Engineering at The University of Texas at Dallas. 800 West Campbell Rd. Richardson, TX $75080{ }^{5}$ Department of Immunology, Institut Pasteur, Paris, France ${ }^{6}$ These authors contributed equally: Michael A. Luzuriaga, Fabian C. Herbert.

To whom correspondences should be addressed: Nicole.DeNisco@UTDallas.edu and Gassensmith@utdallas.edu

\section{Supplemental Data}

\section{Biolegend ELISA Kits}

IFN-Y: Sensitivity $4 \mathrm{pg} / \mathrm{mL}$ and Standard range $15.6-1,000 \mathrm{pg} / \mathrm{mL}$

TNF- $\alpha$ : Sensitivity $4 \mathrm{pg} / \mathrm{mL}$ and Standard range $7.8-500 \mathrm{pg} / \mathrm{mL}$

IL-17: Sensitivity $8 \mathrm{pg} / \mathrm{mL}$ and Standard range $15.6-1,000 \mathrm{pg} / \mathrm{mL}$

IL-4: Sensitivity $1 \mathrm{pg} / \mathrm{mL}$ and Standard range $2.0-125 \mathrm{pg} / \mathrm{mL}$

IL-2: Sensitivity $1 \mathrm{pg} / \mathrm{mL}$ and Standard range $2.0-125 \mathrm{pg} / \mathrm{mL}$

IL-6: Sensitivity $2 \mathrm{pg} / \mathrm{mL}$ and Standard range $7.8-500 \mathrm{pg} / \mathrm{mL}$ 
A)

A) $10 \mathrm{~min}$

B) $20 \mathrm{~min}$

C) $30 \mathrm{~min}$

D) $60 \mathrm{~min}$
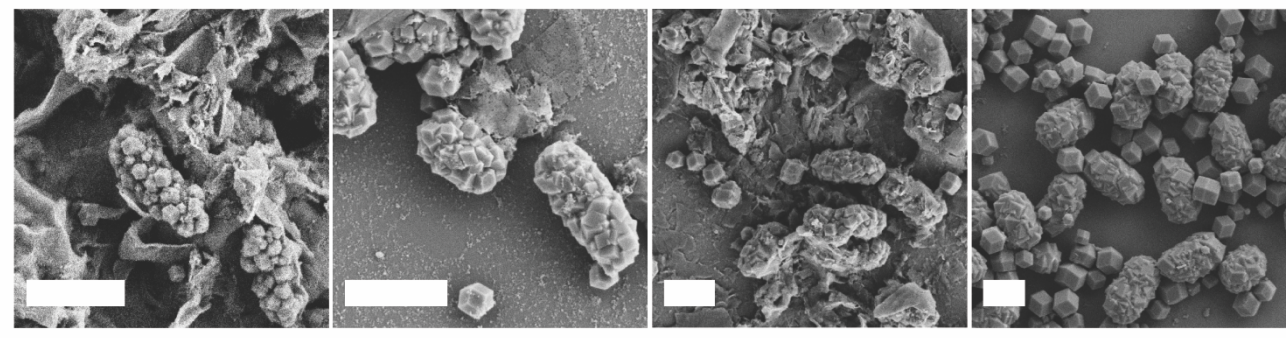

\section{E)}

E) $\quad 75 \mathrm{mM}$

F) $100 \mathrm{mM}$

G)

$125 \mathrm{mM}$

H) $\quad 150 \mathrm{mM}$

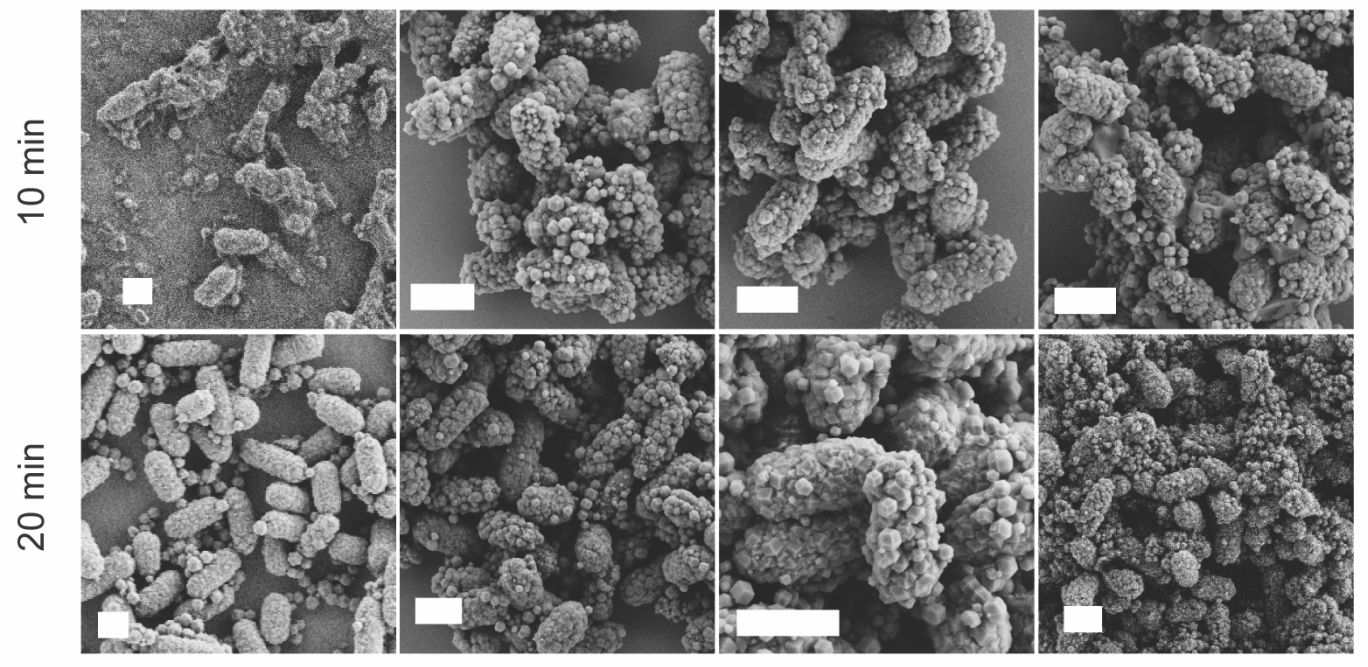

I)
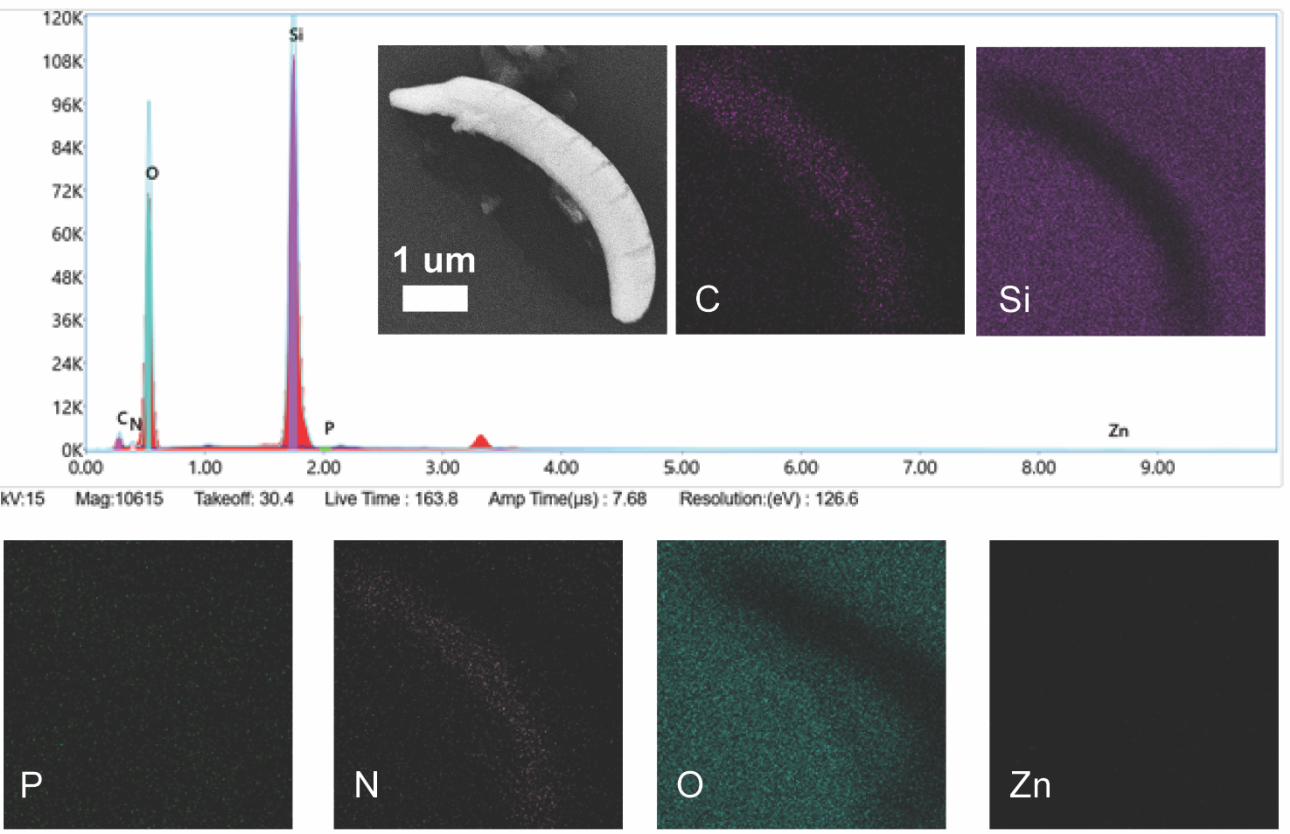

Fig. S1 Shorter incubation times and saline reduce the amount of free ZIF-8. Live CFT073 was incubated with an aqueous solution of zinc and 2-methylimidazole and left at room temperature for A) 10 minutes, B) 20 minutes, C) 30 minutes, or D) 60 minutes. After each time point, the sample was centrifuged to remove excess zinc and 2-methylimidazole and washed with water three times. CFT@ZIF encapsulation was performed with $1 \mathrm{mg}$ of CFT073 in E) $75 \mathrm{mM}, \mathrm{F}) 100 \mathrm{mM}, \mathrm{G}) 125 \mathrm{mM}$, or H) $150 \mathrm{mM}$ saline solutions for either 10 or 20 minutes to reduce cell bursting and the amount of free ZIF-8. I) Element distribution of CFT073 by EDX. The graph shows the presence of carbon, oxygen, nitrogen, and phosphorus. Image maps show carbon and nitrogen signals come from CFT073. White scale bars are $2 \mu \mathrm{m}$, unless stated otherwise. 


\section{Long-Term Stability}

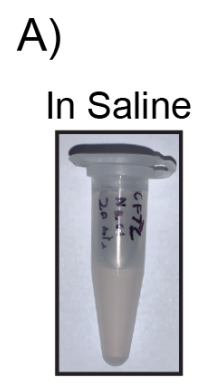

B)

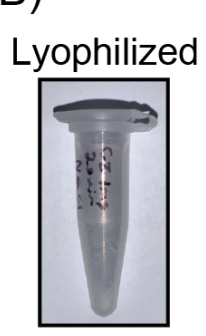

Day 0
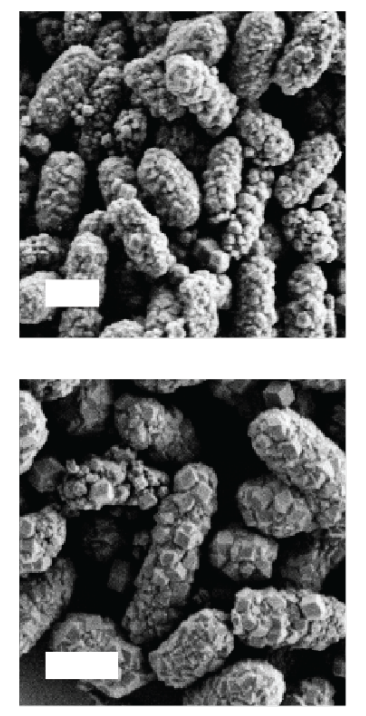

Day 7
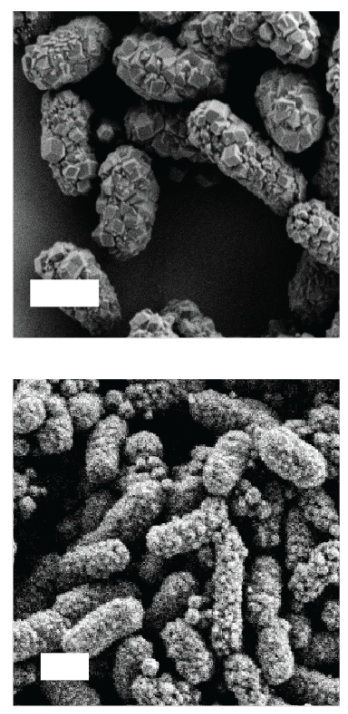

Day 21
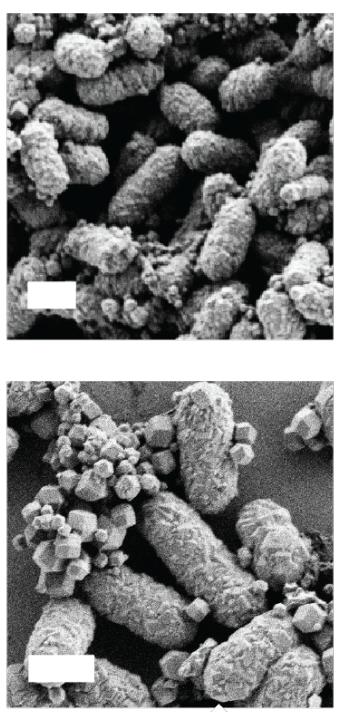

Day 28
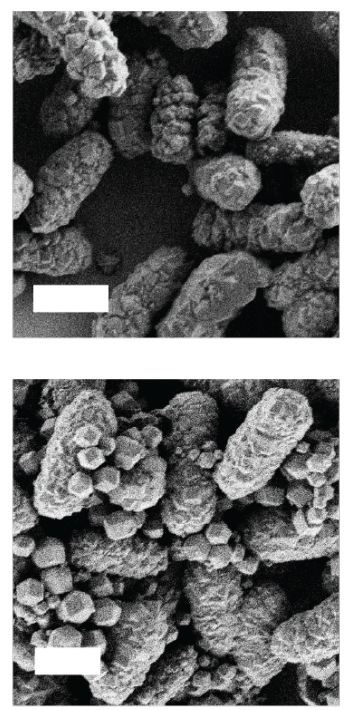

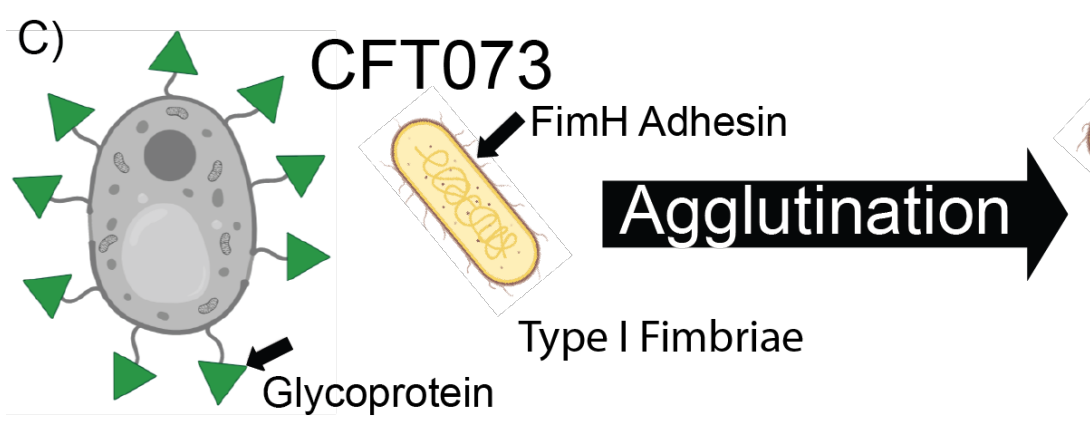

Yeast

D)
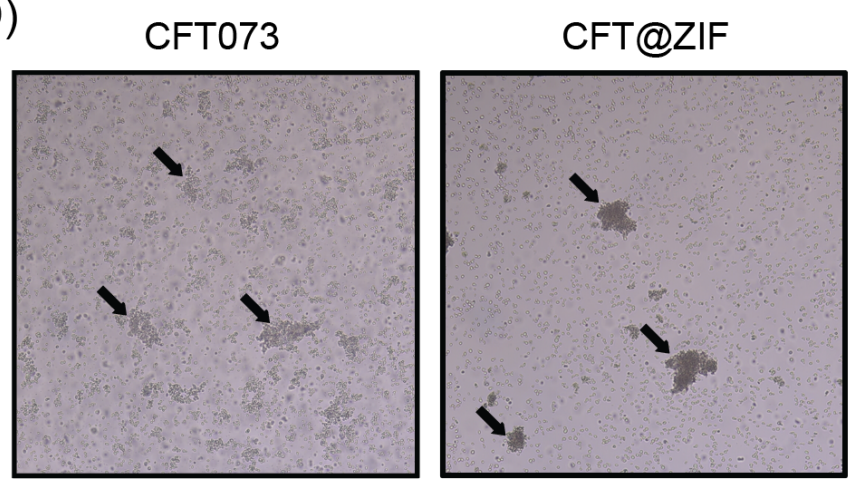

CFT-Fixed

CFT-Heat
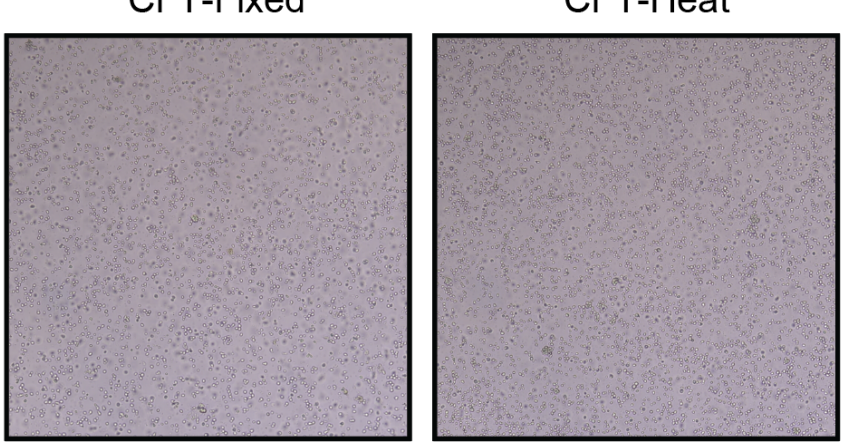

Fig. S2 CFT@ZIF Stability and Agglutination Assay. The stability of CFT@ZIF in A) 0.9\% saline solution and B) after lyophilization. Both formulations were imaged by SEM at Day 0, 7, 21, and 28. White scale bars are $2 \mu \mathrm{m}$. C) An illustration of the principle of agglutination assay. In this qualitative assay the FimH adhesin protein in type 1 fimbriae of CFT073 bind sugar moieties, specifically mannose. Saccharomyces cerevisiae yeast contain large amounts of mannose in their outer cell wall in the form of glycoprotein mannoprotein. This interaction forms large, crosslinked clumps called agglutinates which are clearly visible in light microscopy. D) The agglutination assay was tested at $1.0 \times 10^{8} \mathrm{CFU} / \mathrm{mL}(\mathrm{OD}=0.2)$ for CFT073 and CFT@ZIF and $2.0 \times$ $10^{8} \mathrm{CFU} / \mathrm{mL}(\mathrm{OD}=0.4)$ for CFT-Fixed and CFT-Heat and shows only CFT073 and CFT@ZIF retains binding with yeast. Whereas, CFT-Fixed and CFT-Heat lose binding after treatment. 


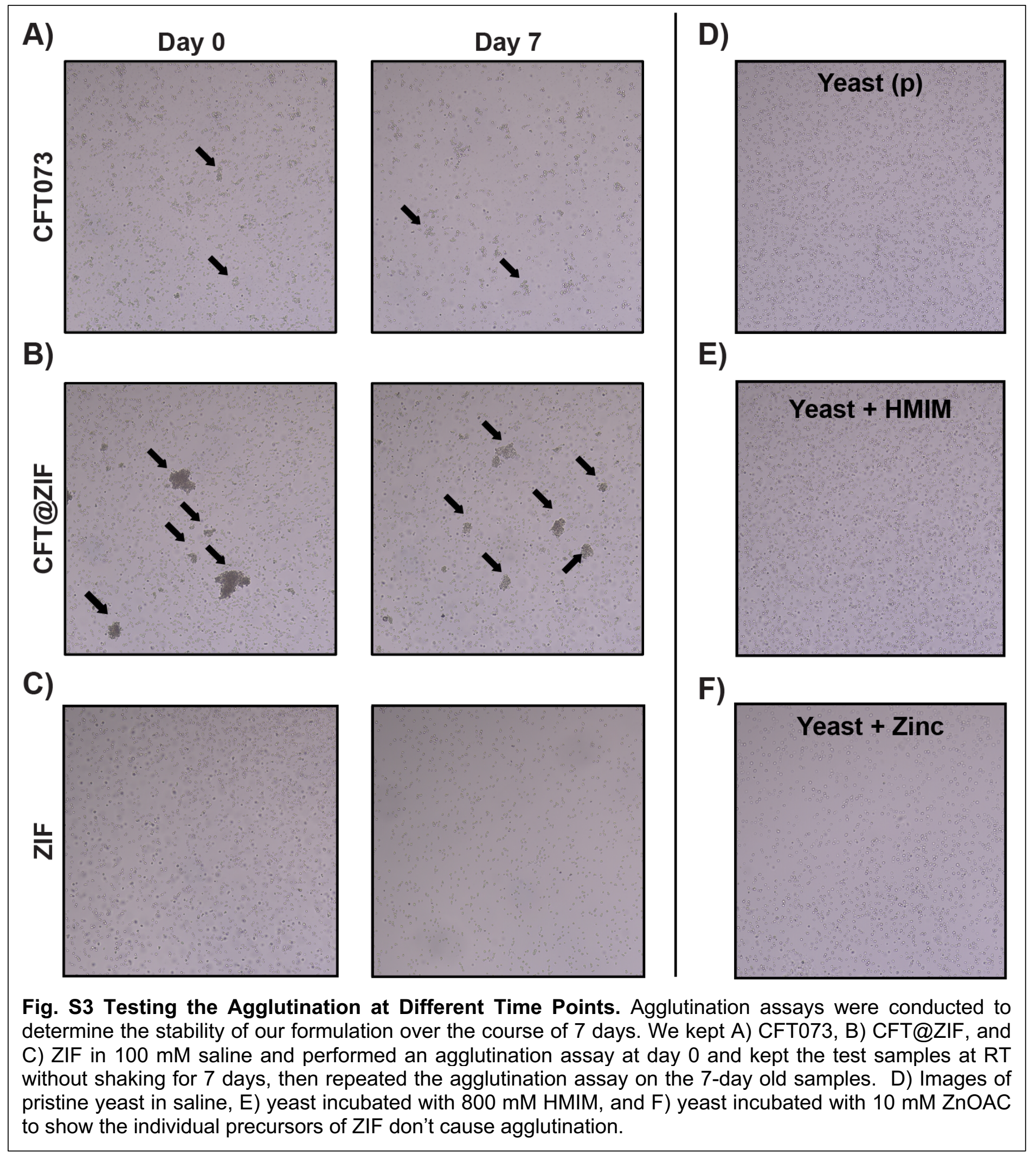



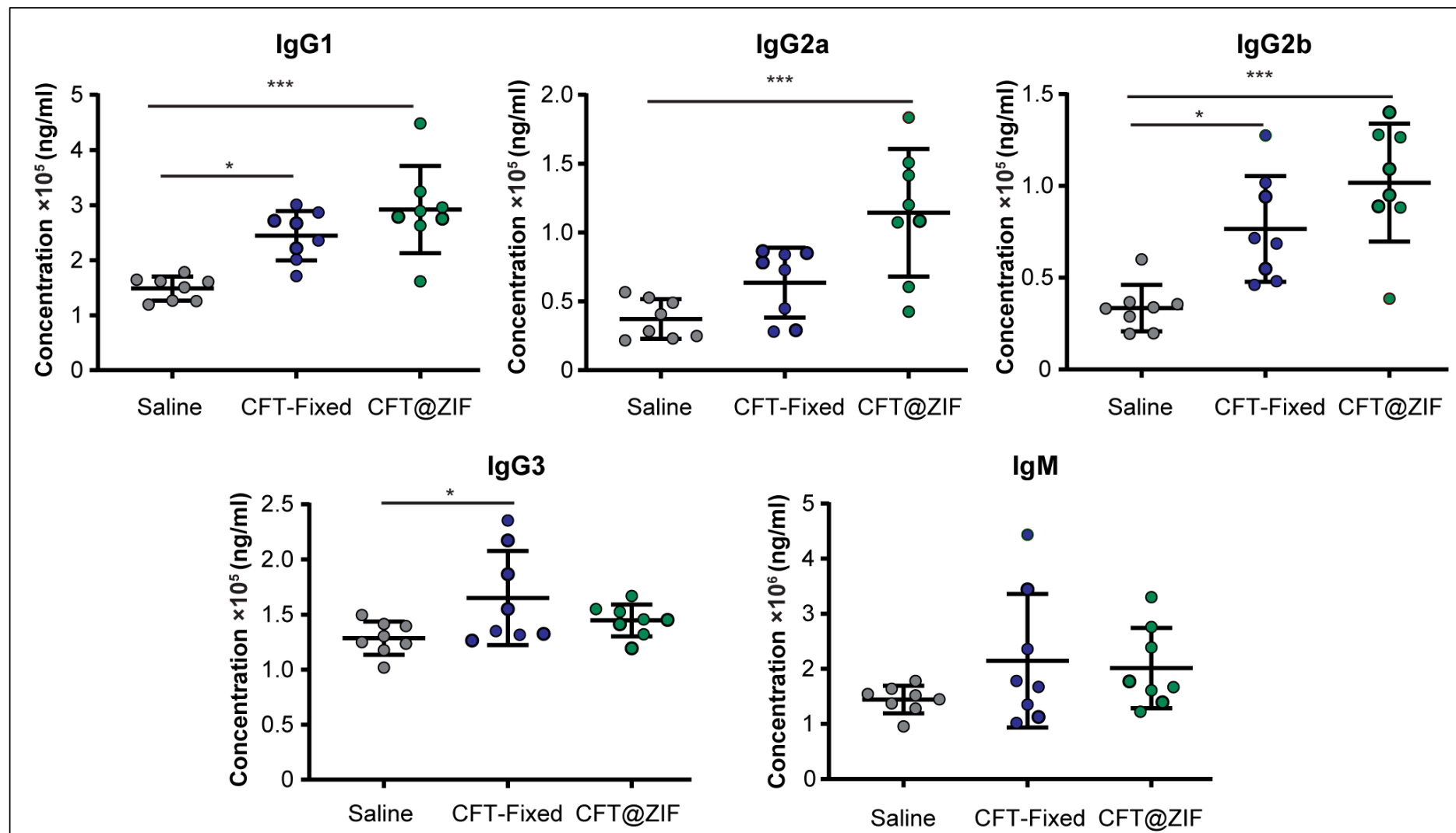

Fig. S4 IgG Subclass Production. Mice $(n=8)$ were vaccinated following the schedule in Figure $\mathbf{2 C}$ and on day 21 blood was collected to obtain serum. The antibody subclasses IgG1, IgG2a, IgG2b, IgG3, and IgM was measured. Statistical significance was calculated using two-way ANOVA with Tukey's multiple comparison post-test $\left({ }^{*} p<0.05,{ }^{* *} p<0.01,{ }^{* * *} p<0.0005,{ }^{* * * *} p<0.0001\right)$. 


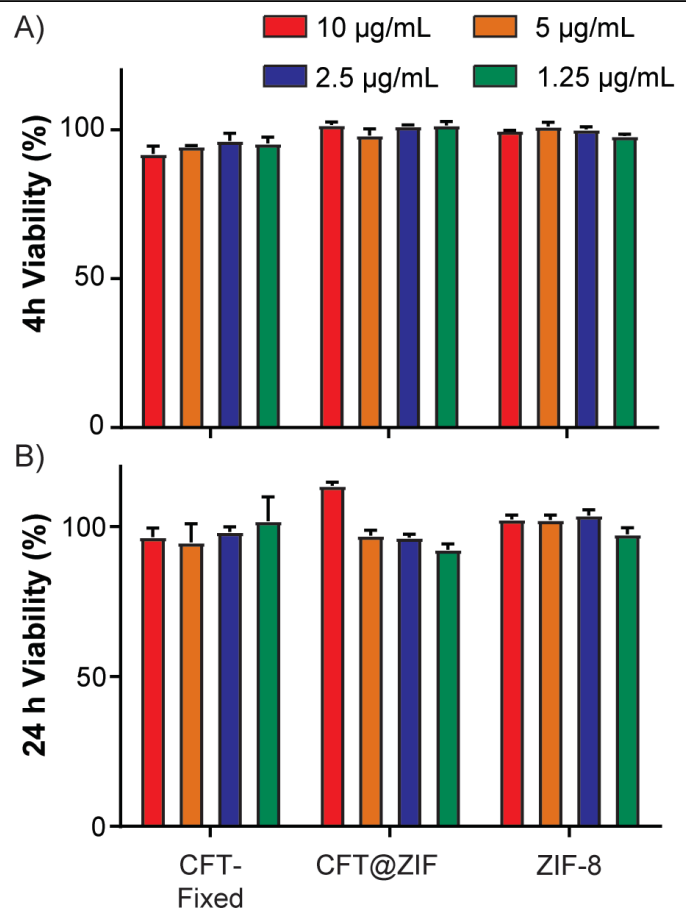

C) DAPI/DNA WGA/Membrane smURFP/CFT073 Merged
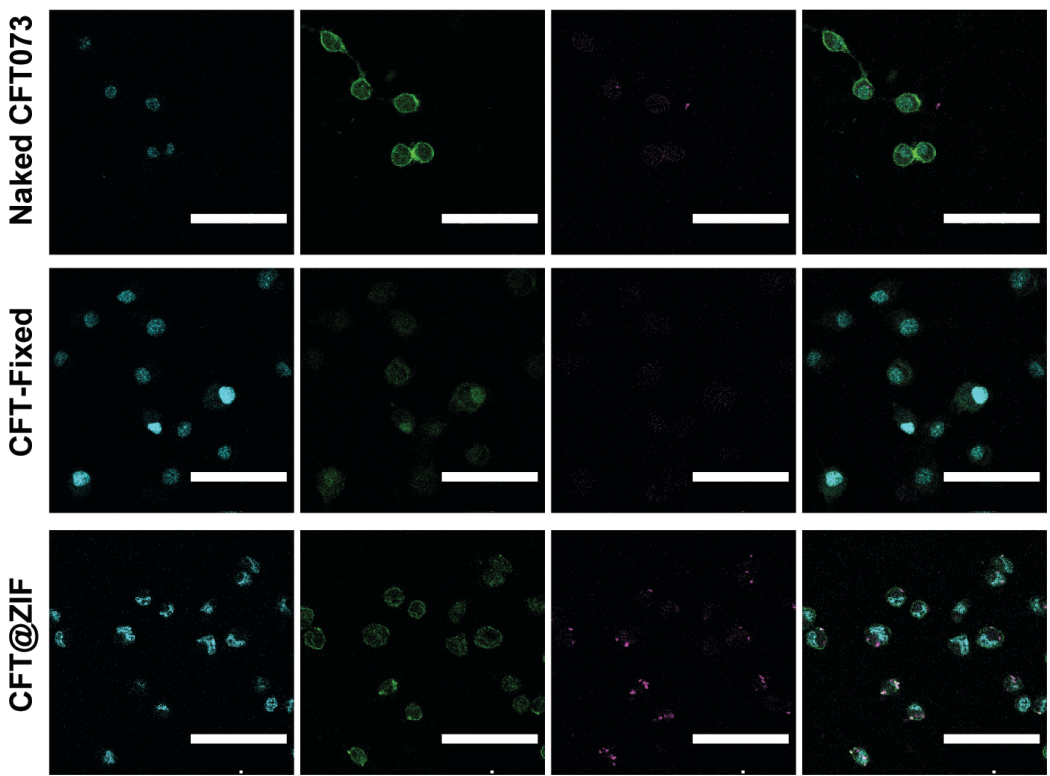

D) $\left.{ }^{100}\right] \quad$ Before Low pH Washing

F)
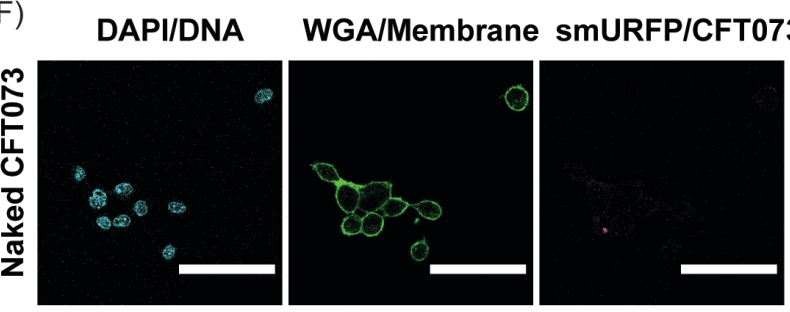

Merged

E)
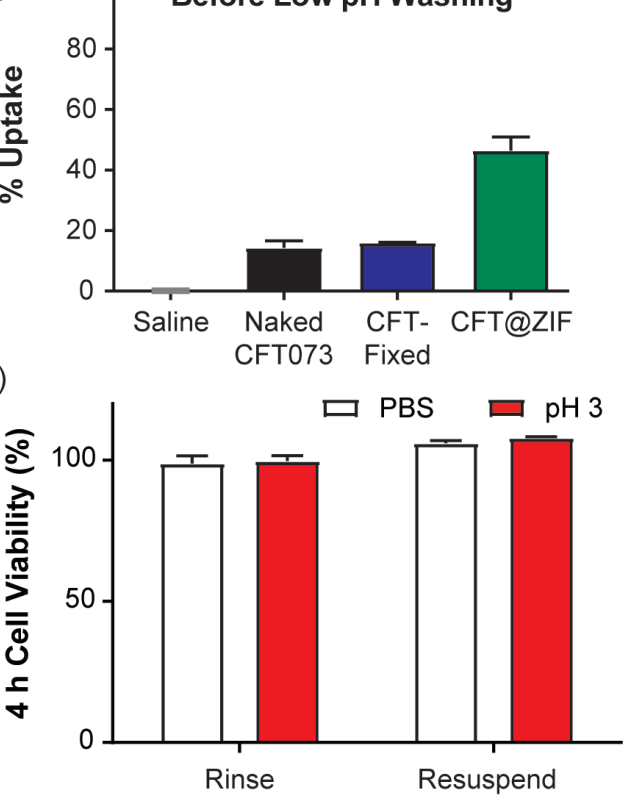
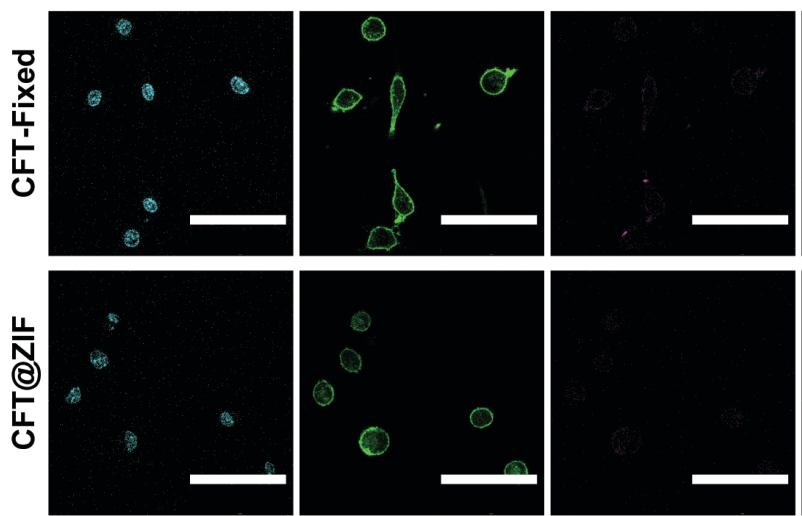

Fig. S5 Viability and CFT@ZIF Iow pH wash study. The viability of CFT-Fixed, CFT@ZIF, and ZIF was tested at different concentrations on RAW 264.7 macrophages for A) $4 \mathrm{~h}$ and B) $24 \mathrm{~h}$. Before low pH wash C) Representative confocal micrographs $(\mathrm{N}=10)$ of smURFP expressing naked CFT073, CFT-Fixed, and CFT@ZIF incubated with RAW 264.7 macrophages for $4 \mathrm{~h}$. Scale bar $=50 \mu \mathrm{m}$. D) Bar graphs of flow cytometry smURFP fluorescence $(\mathrm{N}=3)$ without $\mathrm{pH} 3$ washing of cells measure both surface bound and internalized bacteria. E) We tested the $\mathrm{pH} 3$ washing on the RAW 264.7 macrophages to confirm the washes would not be toxic to the cells. The rinse group was just incubated with $\mathrm{pH} 3$ solution for 5 min and the resuspension group used a $1 \mathrm{~mL}$ pipettor to aspirate the $\mathrm{pH} 3$ solution 10 times, followed by a 5 min incubation. Both samples were centrifuged to remove $\mathrm{pH} 3$ solution and another aliquot of $\mathrm{pH} 3$ solution was added-this was repeated for a total of 3 times. The next set of data is following washing the cells at low $\mathrm{pH}$ to remove surface-bound bacteria: $F)$ Representative confocal micrographs $(\mathrm{N}=10)$ of smURFP expressing naked CFT073, CFT-Fixed, and CFT@ZIF incubated with RAW 264.7 macrophages for $4 \mathrm{~h}$ and washed with $\mathrm{pH} 3$ buffer. Scale bar $=50 \mu \mathrm{m}$ 


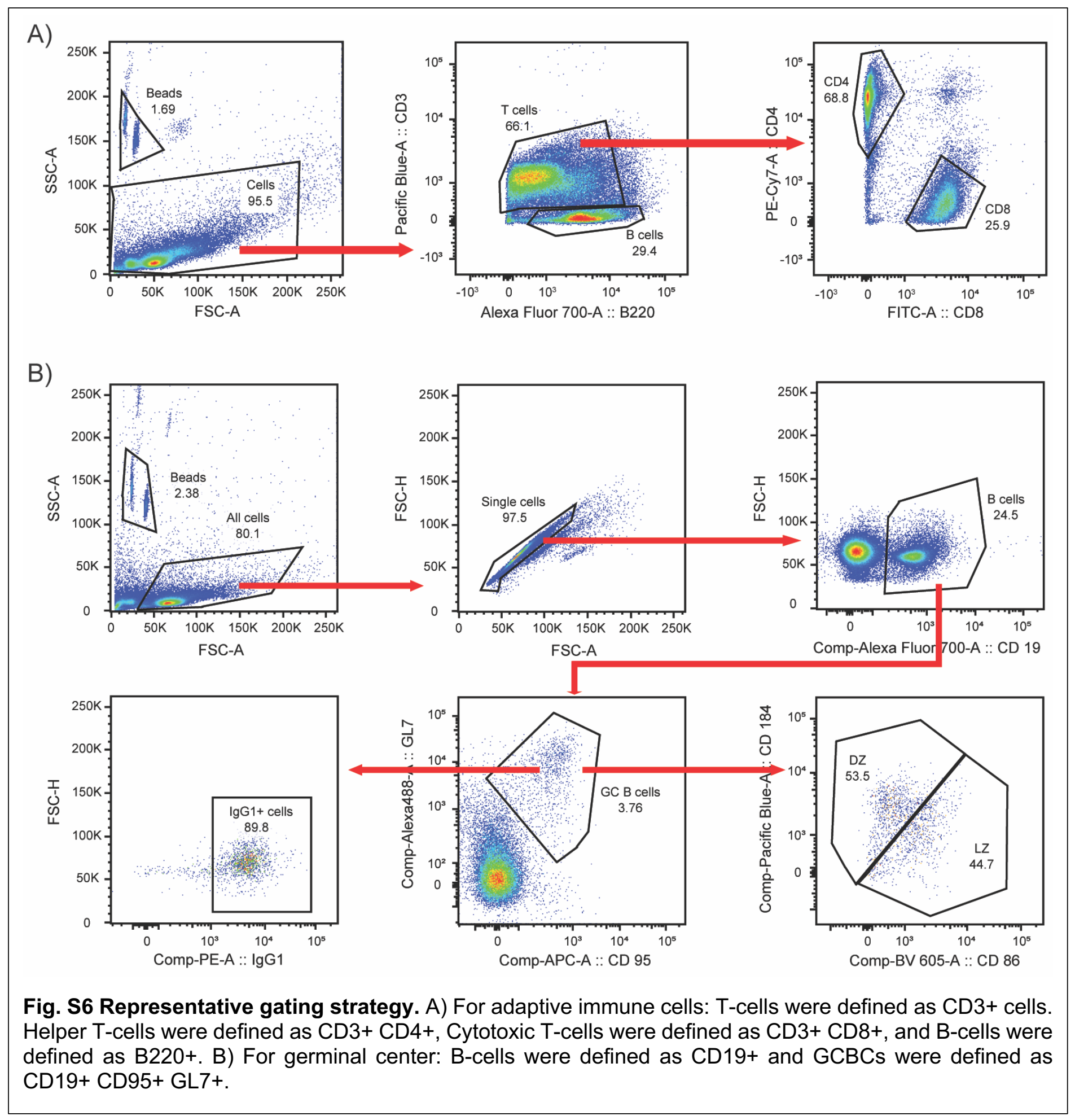

